\title{
Finding Homogeneity in Heterogeneity-A New Approach to Quantifying Landscape Mosaics Developed for the Lao PDR
}

\author{
Peter Messerli • Andreas Heinimann • Michael Epprecht
}

Published online: 21 May 2009

(C) The Author(s) 2009. This article is published with open access at Springerlink.com

\begin{abstract}
A key challenge for land change science in general and research on swidden agriculture in particular, is linking land cover information to human-environment interactions over larger spatial areas. In Lao PDR, a country facing rapid and multi-level land change processes, this hinders informed policy- and decision-making. Crucial information on land use types and people involved is still lacking. This article proposes an alternative approach for the description of landscape mosaics. Instead of analyzing local land use combinations, we studied land cover mosaics at a meso-level of spatial scale and interpreted these in terms of human-environmental interactions. These landscape mosaics were then overlaid with population census data. Results showed that swidden agricultural landscapes, involving $17 \%$ of the population, dominate $29 \%$ of the country, while permanent agricultural landscapes involve $74 \%$ of the population in $29 \%$ of the territory. Forests still form an important component of these landscape mosaics.
\end{abstract}

Keywords Landscape mosaics · Land use - Land cover · Meso-level · Lao PDR · Swidden agriculture

P. Messerli $(\bowtie) \cdot$ A. Heinimann $\cdot$ M. Epprecht Swiss National Centre of Competence in Research (NCCR) North-South, Centre for Development and Environment (CDE), Institute of Geography, University of Berne,

Hallerstrasse 10,

3012 Berne, Switzerland

e-mail: Peter.Messerli@cde.unibe.ch

A. Heinimann

e-mail: Andreas.Heinimann@cde.unibe.ch

M. Epprecht

e-mail: michael.epprecht@cde.unibe.ch

\section{Introduction}

One of the numerous challenges in the field of sustainability science relates to the call for a new mode of collaboration between scientists and decision-makers (Kates et al. 2001; McMichael et al. 2003). More concretely, any such new collaboration should comprise two key features. First, rather than being driven exclusively by academic interests and inquiry, research agendas should emerge from a close dialogue to identify the knowledge needs and gaps between decision-makers and researchers. Second, research results should support informed and evidence-based decision-making. Hence, the levels and scales at which results are aggregated and insights are produced can not ignore the levels and scales at which most relevant decisions are being taken (Cash et al. 2003).

Within land change science, an important component of sustainability research, the call for linking knowledge production with the needs of policy- and decision making, reinforces a fundamental challenge related to describing human-environmental interactions beyond the local context. Land change science has drawn attention to the strong variation of human-environmental interactions in time and space (e.g. Lambin and Geist 2004; Lambin et al. 2003; Verburg et al. 2009). As a growing number of factors at multiple spatial scales influence land use and land cover, and as these factors interact in chain-linked or nested ways (Hurni 1996), they produce dissimilar land cover/use outcomes and thereby reinforcing the uniqueness of any local context (Ostrom 2007; Turner et al. 2007). The resulting limited validity for out-scaling and generalization has also been referred to as the 'one place-one time syndrome' (Woodcock and Ozdogan 2004). Accordingly, a large body of land use literature consists of case studies dealing with human-environmental interactions at the local 
scale. Only a limited number of studies and research initiatives have tackled the issue of linking land cover change to underlying processes at higher spatial scales, out of which the hotspot approach (Achard et al. 2002; Lepers et al. 2005; Mittermeier et al. 2005; Myers et al. 2000) and the meta-analysis approach (Geist and Lambin 2001, 2004; Rudel et al. 2000) are particularly noteworthy. Although these have been interesting initiatives, an operational solution to integrate land cover information with land use processes at a meso-level scale has not yet been found (Heinimann 2006; Verburg et al. 2009).

In contrast with this knowledge gap, decision-making on land use at these levels is becoming increasingly relevant. As land resources in a globalized world provide ecosystem goods and services for stakeholders at higher levels and more distant places (Foley et al. 2005; GLP 2005), decisions and policies from sub-national to international level are becoming increasingly important. At these levels, inventories of land cover are commonly available but knowledge on social-environmental interactions is missing, leading to a growing disconnection between knowledge generation and decision-making.

These problems are very prominently illustrated in the Lao PDR, a landlocked country in mainland Southeast Asia (see Fig. 2). This country, which is the geographical focus of this article, has a relatively small and unevenly distributed population thus making its unused land resources a major development asset (Messerli et al. 2008). With recent annual economic growth rates of around $8 \%$ and an essentially natural resource-based economy (World Bank 2008b), this asset is yet under considerable pressure (Government of Lao 2000; Hirsch 2000, 2001; Rigg 2006). Crucial decisions will have to be taken in the near future on the unavoidable trade-offs between use and conservation of land and natural resources.

At a time when an increasing number of external actors are claiming access to land resources, more and more development interventions are being implemented across the country (Ducourtieux et al. 2005; Fullbrook 2006; Parnwell et al. 1996; Woods 2003). These influences lead to an ever-increasing fragmentation of spatial contexts in terms of development potentials and constraints (Badenoch 1999; Messerli and Heinimann 2007). The rural areas of the Lao PDR, which until recently could be spatially differentiated by few key factors, are currently facing a rapidly rising number of spatially relevant development drivers such as the growing infrastructure networks, the extended reach of public policies, services and market opportunities, the availability of off-farm employment in commercial agriculture or mines, etc. Thereby, spatial units with similar development potential and problems become more and more fragmented and manifest ever smaller geometries. This, in turn, leads to the dilemma between the urgent need for knowledge to support evidence based decision-making on the numerous land use interventions on the one hand, and the growing difficulty of understanding the particularities of the differentiated and fragmented development spaces on the other. This gives rise to a growing uncertainty and the sustainable management of land resources fades further out of sight. Meanwhile, the most basic questions remain unanswered: What is the current extent and availability of different basic land use types such as swidden agriculture, permanent, or commercial agriculture? What share of the Lao population is involved in each? What type of land use implies what trade-off between degradation and conservation of land resources?

Information to answer such questions can be gained through a considerable amount of case studies carried out in different parts of the country. However the validity and reach of their results is often confined to very limited geographical areas. Aggregated information covering the entire country is scarce and of doubtful quality. Reasons for that are the often difficult and contested definitions of land use categories such as swidden cultivation (Mertz et al. 2009a), the quality of data coming from agricultural reporting systems that have to correspond to governmental plans, and a high variety of land cover inventories with different data sets, methodologies and classification systems. As a result, data on the extent of land use systems vary considerably (Padoch et al. 2007; Schmidt-Vogt et al. 2009) and the attribution of people involved in each of these systems is even more difficult, (Mertz et al. 2009b; Messerli 2004).

We hope to contribute to overcoming this knowledge gap by presenting an alternative approach that allows the linking of land cover information with land use processes at a meso-level of spatial scale, i.e. at the district to national level. This can be achieved by describing and quantifying landscape mosaics, which shall comply with two distinct but complementary characteristics: (a) they refer to geographic areas, which consist of spatial patterns of land cover and represent functional units in terms of humanenvironmental interactions, and (b) they represent meaningful spatial geometries that can be related to and overlaid with other spatial data layers, namely socio-economic data derived from population census and household surveys.

\section{An Alternative Approach to Describing Landscape Mosaics}

The notion of landscape mosaic owes much of its appeal to the promise that its spatial patterns reveal information about the underlying social and environmental processes and hence the human-environmental interactions ( $\mathrm{Wu}$ and Hobbs 2007). In other words, this approach of describing 
landscape mosaics should allow, not only the integration of land cover inventories with land use processes over larger areas, but it should also offer the potential of contributing to the generalization of knowledge, aggregation and scaling (Levin 1997).

In an analysis of the already described limitations of current research initiatives, we can observe one underlying problem. This is epistemological in nature and becomes apparent when taking a social science perspective. We can only relate land cover changes to human action if we understand who the actors influencing the land are, and what the intention and meaning of their activities is. In other words, the researcher has the difficult task of "having to interpret a social world which is already interpreted by the actors that inhabit it" (Giddens 1991). Accordingly, such an interpretation can only be meaningful if it is done contextually, i.e. performed within the specific social, political, and economic spheres and related to concrete space and time (Long 2001; Wiesmann 1998). Against this backdrop the fundamental limitation of generalizing land use process through up- and out-scaling becomes clear. The interpretation is only valid in a specific context-often restricted to a very local setting - and becomes void as soon as we enter a new context.

As shown in Fig. 1, the first step in frequently applied approaches to describing landscape mosaics often consists of interpreting human-environmental interactions in a local context allowing the translation of land cover into land use information (step A1). The stumbling block often lies in step A2. When analyzing spatial patterns of land uses to describe landscape mosaics, the contextual interpretations of a few land cover patches are extrapolated to other places or to higher levels of aggregation. For these, the contextual
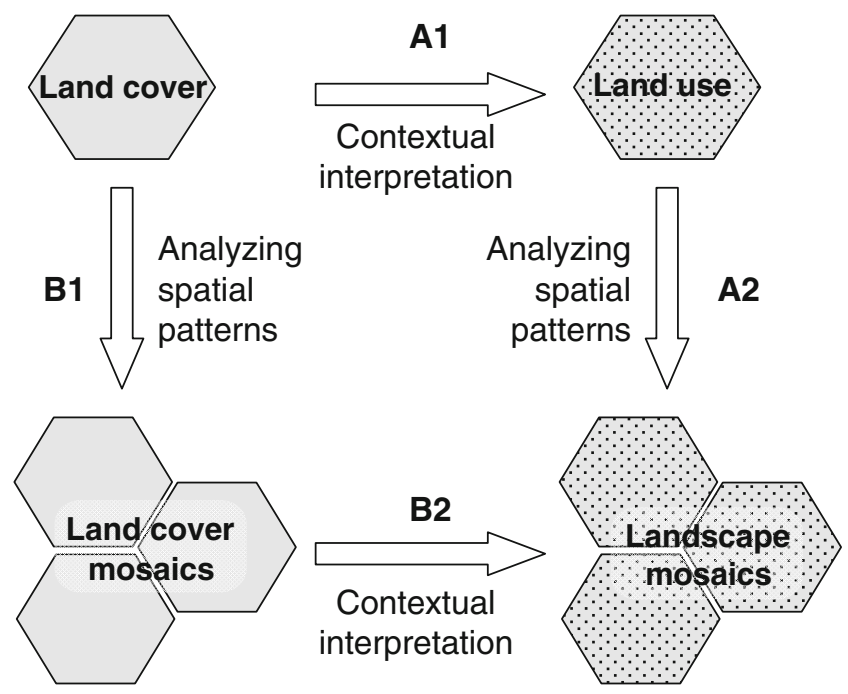

Fig. 1 From land cover information to landscape mosaics. While pathway A depicts the ordinary approach, pathway B depicts the new approach proposed in this paper interpretation is often no longer applicable and the process information contained in the landscape mosaic is flawed. While for example a secondary forest patch in a context of swidden cultivation may be used mainly as fallow land, a similar secondary forest in a different ethnic context may be of spiritual value or in a context of permanent agriculture as a source of timber and non-timber forest products.

Taking these difficulties into account, we propose an alternative approach to the description of landscape mosaics. This approach consists of first, analyzing patterns of spatial coexistence of different land cover types without trying to interpret their meaning in terms of land use (B1). This will result in land cover mosaics, which are defined as a specific combination of land cover patches within a given geographical area. Only then, are the resulting land cover mosaics interpreted within a socio-political context that corresponds, in terms of scale and spatial coverage, to the development issues at stake. In other words, we do not ask for the use of a single land cover patch and then try to extrapolate this information over larger areas. Rather, we ask in what spatial compositions (i.e. land cover mosaics) do land cover patches occur across the territory, and then interpret these compositions in terms of human-environmental interactions. The resulting landscape mosaics no longer contain precise information on single land use patches but provide an interpretation of land cover mosaics as spatial manifestations of different land uses in the rural Lao PDR.

\section{Methods}

Study Area and Land-Cover Data

In Lao PDR the deficits in information and knowledge for decision- and policy-making in terms of land use are very important from provincial to national level. Therefore this study attempts to provide information covering the entire territory of the Lao PDR. The Lao PDR is a landlocked, mountainous country, surrounded by Cambodia, China, Myanmar, Thailand and Vietnam. It is a multi-ethnic and predominantly rural society in which most of the population depends on agriculture. In the mountainous regions, swidden agriculture is widely practiced, while in the alluvial plains of the Mekong and its tributaries irrigated paddy rice dominates the landscape. In 2002, forests still covered $41.5 \%$ of the country (GOL 2005) but are disappearing at alarming rates of about 53,000 ha per annum (World Bank 2008a). About 33\% of the country's 5.6 million people live below the national poverty line (Epprecht et al. 2008). With a per capita GDP of US\$ 485 in 2005 (IMF 2008), it is one of the poorest countries in the East Asia and Pacific Region. The respective country's 
human development ranking is 130rd among 177 countries (UNDP 2007). With this level of poverty, the country's natural resource base is of critical importance in poverty alleviation and growth.

Land cover maps were obtained from the Ministry of Agriculture and Forestry. The inventory captured the situation in 2002 and is based on visual interpretation of SPOT satellite images at scales of 1:50,000 and 1:100,000, for forest and land cover mapping, and field verification. The original land cover data comprises 22 categories, which we have aggregated into eight main land cover types: forests, open forests, bush and shrub, grassland, swidden agricultural fields, permanent agriculture, paddy rice, and other categories (rock, etc.). It should be noted, that the identified swidden agricultural fields comprise only the burnt plots, while any fallow swidden land would have to be found under open forests, bush, or grassland. This makes a quantitative assessment of the actual extent of swidden agriculture impossible based on the original land cover data. Finally we would like to point out that even though land cover data for different points in time exists in Lao PDR, the differences in imagery, classification methods, and interpretation made it impossible to focus on dynamics of land cover change. This approach is hence limited to an assessment of one point in time.

\section{Describing Land Cover Mosaics (Step B1)}

Following the overall approach proposed in Fig. 1, we first analyzed spatial patterns of land cover to identify what we call land cover mosaics. For each pixel of $50 \times 50 \mathrm{~m}$ of the land cover map we analyzed the land cover categories of all neighboring pixels within an area of $5 \times 5 \mathrm{~km}$. We thereby recorded the presence or absence of each land cover category within the window in a binary way (yes/no). Given the unequal share of land cover classes across the country (e.g. paddy vs. forests), an inverse weighting was applied to determine the threshold at which a patch was taken into account or not. This yielded information about the composition of land cover within this window, which was attributed to the central pixel. Using a moving window technique, we were able to attribute to every pixel in this way a code denoting the land cover composition within its surrounding window. Adjacent pixels with the same code, i.e. the same composition of neighboring pixels, then clustered into a land cover mosaic (see Fig. 2).

The window size is obviously a key factor determining the resulting land cover mosaics in terms of size, number, and combination of patches. The choice of $5 \mathrm{~km}$ was based on a study showing the impact of accessibility on land cover change in the Lao PDR (Heinimann 2006). Given the fact that the rural population in the country lives in villages, Heinimann (2006) analyzed the distance from the village at which the impact on land cover change fades out. This allowed the approximation of the average reach of rural actors and hence supporting the choice of a meaningful window size.

Contextual Interpretation of Landscape Mosaics (Step B2)

The preceding step has allowed describing land cover mosaics, which are defined as a specific combination of land cover patches within a given geographical area. We now proceeded to a contextual interpretation of these mosaics. In contrast to the preceding step that can be performed on land cover data alone, the next step must take into account the social, economic and political aspects of the development context in question, and so is not transferable from one context to another. It should be remembered that the precise use of a single land cover patch is no longer the focus of interest but rather the existence of certain land cover mosaics in the overall land use context at a meso-level. Based on the knowledge and expertise gained from the Lao PDR, we focused on two key land use development issues, which are of concern to national policy- and decision-makers:

1. Intensification of land use: In its agricultural vision for the year 2020, the Government of the Lao PDR clearly foresees increased productivity through sedentary and permanent systems (GOL 1999, 2006a). This expected to allow the improvement of food security at the national level and the alleviation of rural poverty, which is still related to swidden agricultural systems. Such systems are held responsible for the deforestation and degradation of natural resources, as well as the low agricultural productivity per surface unit by the parts of the Government of Laos (ibid.). On the other hand, some scholars argue that there is sufficient land available to support the present population without any overall adverse effects on the environment or on the forest resource (Chamberlain and Phomsombath 2002; Raintree 2003). Moreover, there has also been the suggestion that rotational swidden systems remain sustainable and are the most productive means available for achieving food security and meeting livelihood needs (Fox 2000; Raintree 2003; Rigg 2005). For these scholars, the country's Malthusian squeeze is best interpreted as 'policy-induced', i.e. through current policies such as land allocation, and resettlement and village merging. In summary, the reason for the incompatibility of such perspectives, and the absence of a pragmatic dialogue, lies partly in the lack of information and knowledge on which shares of the territory are currently under what intensity of agricultural use, and involving which part of the population and in what places. 


\section{Transformation of land cover patches into a land cover mosaics}

\section{Legend}

\begin{tabular}{|c|c|}
\hline Forest (F) & Swidden fields (Sw) \\
\hline Open forest (Of) & Permanent agriculture $(\mathrm{Pa})$ \\
\hline Shrub and Bush (Sr) & Paddy (Pd) \\
\hline Grass (Gr) & Other (Ot) \\
\hline Paved roads & \\
\hline Mekong river & \\
\hline
\end{tabular}

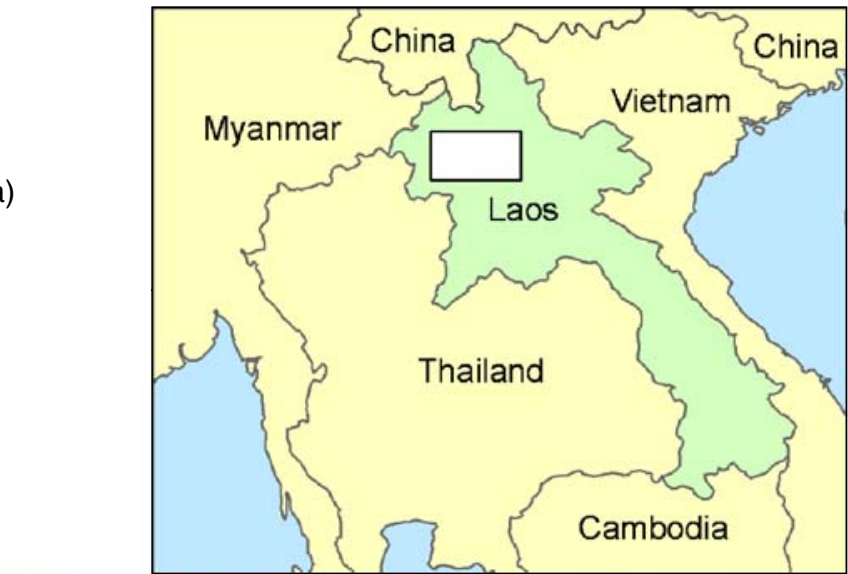

$\begin{array}{llllll}0 & 5 & 10 & 20 & 30 & 40 \text { Kilometers }\end{array}$

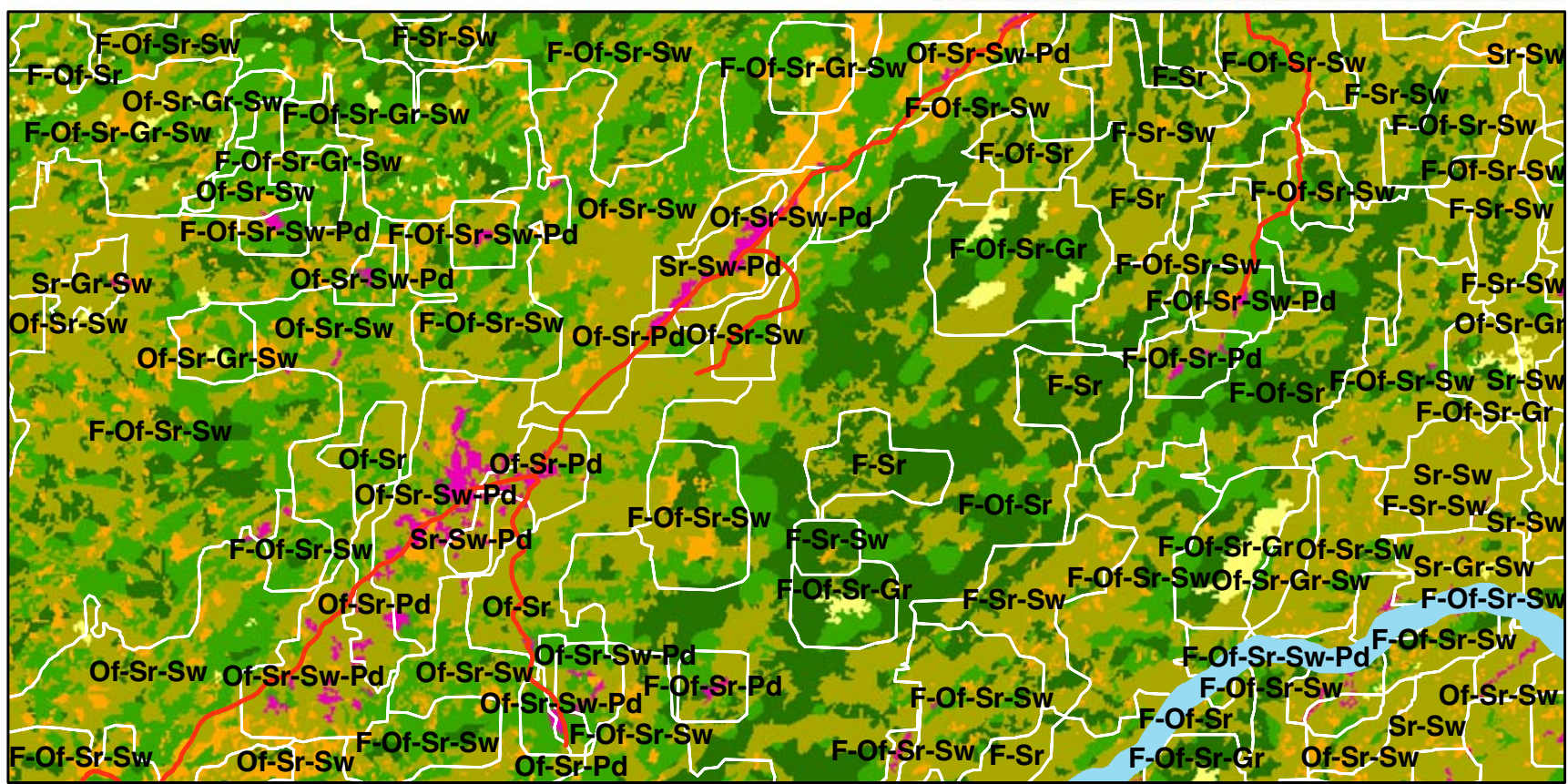

Fig. 2 Transformation of land cover patches into land cover mosaics. Using a moving window technology, each pixel is attributed information about the composition of its neighboring pixels in a $5 \times 5 \mathrm{~km}$ window.

2. Degradation of forests and vegetative cover: Referring to the Lao PDR as the "green jewel of the Mekong"(IUCN 2006), numerous stakeholders unanimously consider the tropical rainforest and the abundant natural vegetation of the country as a key development asset, even if the reasons for this are quite controversial. At the national level, forest and wood products represent an important source of revenue and still comprise a large share of total exports (Qiang and Broadhead 2002). Furthermore, the role of the forests in protecting watersheds for the growing number of hydropower dams is highly valued. At an international level, ecotourism and, in the future, possibly the valuation of ecosystem services such as carbon sequestration or
Pixels manifesting the same composition of neighboring pixels are clustered into land cover mosaics (white borders). The codes correspond to the combination of land cover categories (see above)

biodiversity conservation are becoming more and more important. At the local level, forests and especially secondary forests have also played - and continue to play - a central role in providing the livelihoods of rural families as they still represent an important source of food and provide a large array of other non-timber forest products (NTFPs) (ADB 2001; Rigg 2006; WFP 2007). The high pace of deforestation and forest degradation is therefore an alarming phenomenon, curtailing short and long term development options.

It is not surprising that these two key issues related to land use policy and planning are closely related to each other, and often represent conflicting interests. Correspond- 
ingly, our contextual interpretation of landscape mosaics is based on the question of this trade-off. In other words we ask what a certain land cover mosaic, as derived from step B1 above, represents in terms of agricultural intensification versus deforestation and degradation of the vegetative cover.

Figure 3 illustrates how the land cover mosaics representing specific compositions of land covers are attributed to one of the 16 types of landscape mosaics. Each landscape mosaic is characterized by the presence of the most intensive form of agricultural use and by the least degraded form of vegetative land cover. A swidden cultivation landscape mosaic, for example, is defined as a cluster of land cover mosaics that may be composed of any land cover except permanent agricultural fields or paddy (column C). A further differentiation is made using the specific conditions of forest and vegetation (using rows 14). The two corners A1 and D4 represent the most extreme poles of the trade-off between degradation and use of land resources, while D1 can be considered as a landscape mosaic where agricultural use has been intensified without a concomitant degradation of the vegetative cover. The limitations of the underlying land cover data should however not be forgotten. On the one hand it is a one time data set and we can hence not infer dynamics; on the other hand the data does not allow to fully differentiate between natural and plantation forests.

Following this classification it will be possible to quantify different types of landscape mosaics, revealing not only the share of the territory under a certain type of land use, but also identifying all landscapes where forests are still an important component. This chart is also used as a map legend in Fig. 4, which shows how this interpretation from land cover to landscape mosaics reveals interesting spatial patterns.
Overlaying Landscape Mosaics with Other Data Layers

The definition of landscape mosaics as units representing trade-offs between agricultural use and degradation of forest resources also produced geometries that genuinely depict the different types of human-environmental interactions. These geometries lend themselves to overlays with other spatial data layers without having to revert to other a priori chosen geometries such as watersheds, administrative units, etc.

In the Lao PDR, a parallel research initiative depicting socio-economic data at the highest possible resolution, i.e. at village level, has been launched. Mainly based on the Population and Housing Census 2005 (GOL 2006b), 70 indicators were calculated for each of the 10,547 villages and spatially illustrated in a Socio-Economic Atlas of the Lao PDR (Messerli et al. 2008). This spatial disaggregation of socioeconomic data, which normally is only available as province aggregates, has added considerable value to the data of the Population and Housing Census. Given the fact that in the Lao PDR no village boundaries are available for the depiction of the data, so-called village polygons, based on equidistance of travel time between any two villages, were calculated (Epprecht et al. 2008; Heinimann 2006; Messerli et al. 2008). These village polygons were then intersected with the landscape mosaics allowing the attribution of demographic data from the population census to each landscape mosaic (Fig. 5).

\section{Results}

\section{Describing Land Cover Mosaics (Step B1)}

The analysis of the approximately 92 million pixels containing land cover information within the territory of the
Fig. 3 Table chart illustrating the definition of landscape mosaics based on the trade-off between agricultural intensification on the one hand, and degradation of vegetative cover on the other hand. Each land cover mosaic derived from step B1 is attributed to one of the 16 landscape mosaics. Note that the presence of the most intensive agricultural land cover category in the composition of the land cover mosaic determines the choice of the column. Correspondingly, the least degraded form of vegetative land cover determines the row to which the mosaic will be attributed

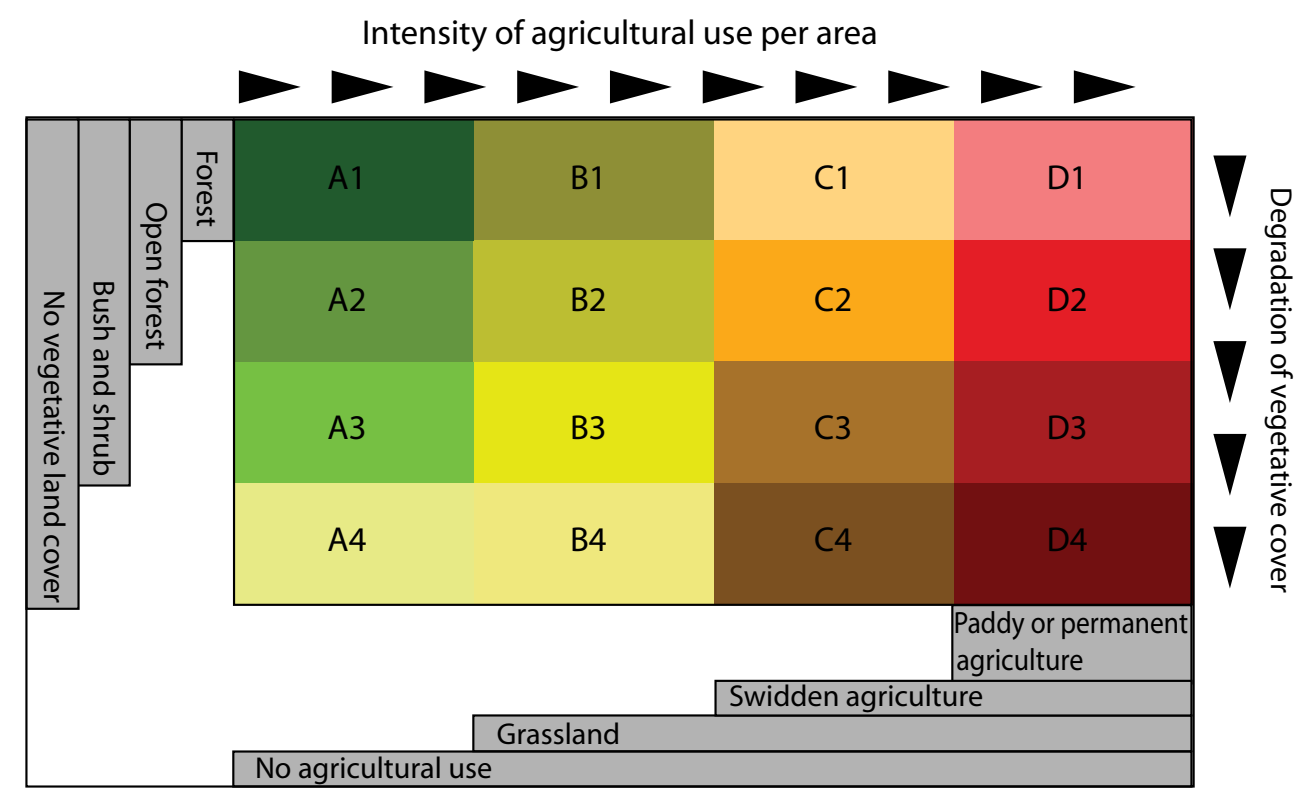




\section{Interpretation of land cover mosaics as landscape mosaics}
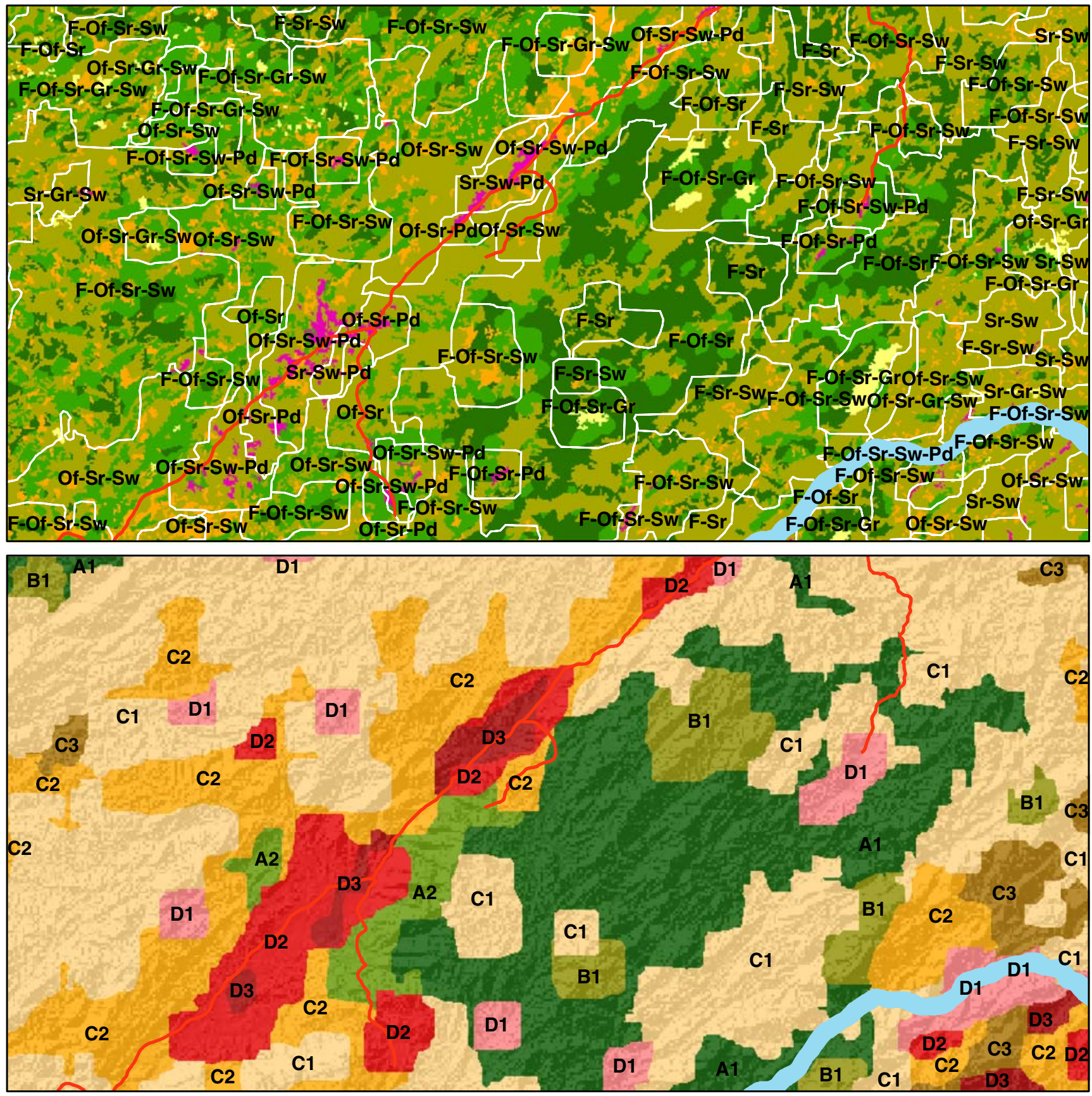

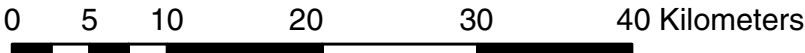

Fig. 4 Illustration of the interpretation of land cover mosaics (above and cf. Fig. 2) as landscape mosaics (below). For the legend of the landscape mosaics please refer to Fig. 3

Lao PDR using moving window technique with a $5 \times 5 \mathrm{~km}$ window resulted in the identification of 3,446 land cover mosaics. Each of these mosaics was composed of one to eight land cover classes and varied in size with a median area of $34 \mathrm{~km}^{2}$. On average, such a land cover mosaic was made up of three different land cover classes.
Even though the eight land cover classes could potentially be combined into 225 different compositions, only 120 actually occurred. Nevertheless, a few of these compositions are very dominant accounting for extensive shares of land (see Fig. 6).

The six most important land cover mosaics together cover $50 \%$ of the territory of the Lao PDR (cf. Table 1). It 


\section{Overlaying landscape geometries with socio-economic village data}
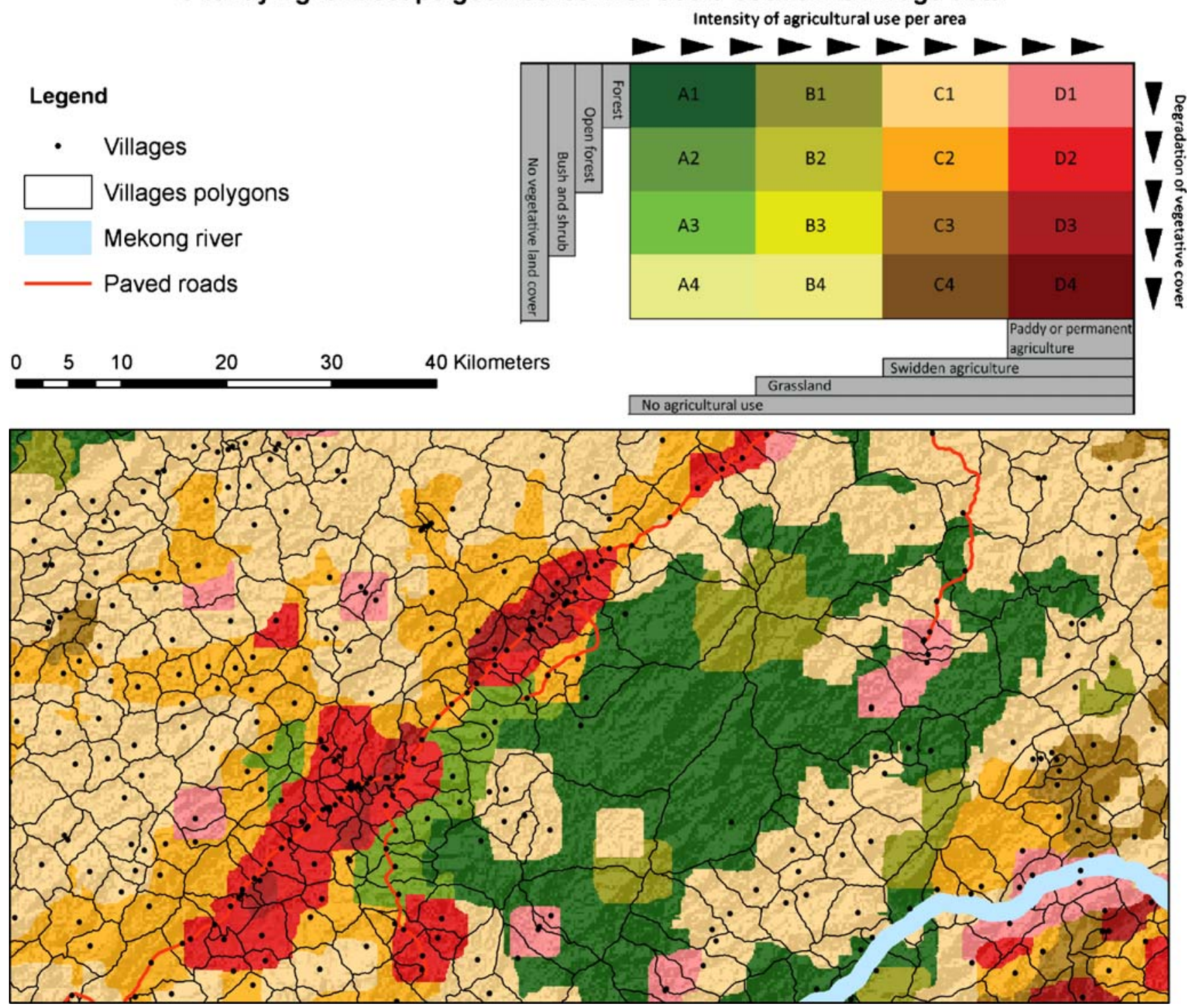

Fig. 5 Overlay between landscape mosaics and village polygons. Resulting intersects allow the attribution of population census data to the different landscape mosaics

is striking that forest patches are part of all of these mosaics. This seems to substantiate the argument that despite the ongoing loss of coherent forest surfaces in Laos, forest patches still play a central role in supporting the livelihoods of rural families as sources of food and other timber and non-timber forest products (NTFPs) (ADB 2001; Rigg 2006; WFP 2007).

Contextual Interpretation of Landscape Mosaics (Step B2)

Against the backdrop of the most salient and controversial issue related to land use policy and decision-making at the national level-the intensification of agriculture versus deforestation and degradation of the vegetative cover-we interpreted the 120 different land cover mosaics as 16 different types of landscape mosaics. This resulted in a map of landscape mosaics of the Lao PDR as well as giving, for the first time, a quantification of the different shares of these landscapes for the country.

Looking at the large scale map of the Lao PDR (Fig. 7) we can observe the general distribution of landscape mosaics across the country. Forested landscapes, without significant agricultural use, cover the central and eastern parts of the country, as well as the southern and northern tips. Landscapes composed of swidden agriculture and different vegetative covers dominate the northern uplands, as well as parts of the Annamite Mountains on the eastern border with Vietnam. Permanent agriculture can be found in 
Fig. 6 Shares of land of the most important land cover mosaics in the Lao PDR. Land cover mosaics result from the composition of a maximum of eight land cover categories within a window of $5 \times 5 \mathrm{~km}$. Out of 225 possible combinations 120 occurred. A small number of compositions make up a large share of the territory

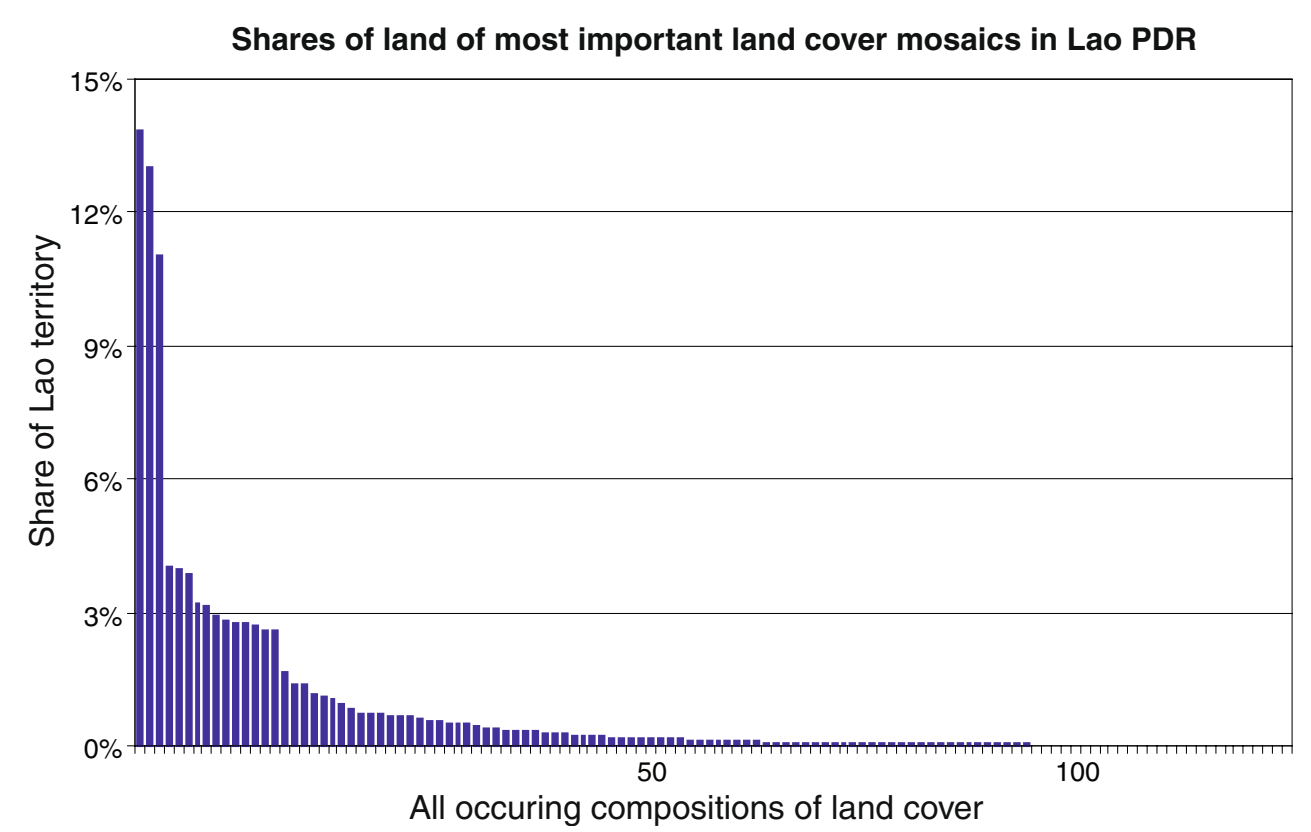

landscapes along the Mekong but is generally more widespread in the south with the exception of the northeastern region around the provincial capital of Xamneua. At a smaller scale we observe that the landscape mosaics mimic the spatial gradients of land cover composition from peripheral to more central areas that extend around the urban centers and along the main roads.

In quantitative terms the chart reveals that in 2002 no agricultural use was detected in $33 \%$ of the Lao territory. Swidden agricultural landscapes, which show no sign of transition into permanent agriculture, and manifest different conditions of the vegetative cover, accounted for a total of $28.2 \%$, or approximately 6,500,000 ha. Finally, permanent agriculture and paddy farming were already dominating landscapes in $29 \%$ of the country. It is remarkable that in 2002 forests still played a very important role in all types of agricultural landscapes. We observed that forests were still a component in $72 \%$ of all Lao landscapes. Furthermore, in $18.4 \%$ of all landscapes, there were at the very least patches of open forests. In other words, most of the swidden and permanent agriculture was still practiced in an environment coexisting with forests ( $77 \%$ of the total swidden and $47 \%$ of permanent agriculture respectively).
Overlaying Landscape Mosaics with Demographic Census Data

As mentioned earlier, this approach to landscape mosaics intends to delineate spatial units, which are genuinely related to the types of human-environmental interactions described above. This allowed the overlay and intersection of the map of landscape mosaics directly with the village data layers emerging from the Population and Housing Census of 2005 (GOL 2006b) and depicted in the SocioEconomic Atlas of the Lao PDR (Messerli et al. 2008). Figure 8 recapitulates the land shares of different landscape mosaics (left) and compares it with the share of the population living in each landscape mosaic (right).

While swidden and permanent agricultural dominated landscape mosaics occupy comparable shares of the Lao territory (28.2\% and $29.0 \%$ respectively), the population is distributed quite differently. A total of $16.9 \%$ of the population live in swidden landscape mosaics, corresponding to about 943,000 individuals or approximately 157,000 households. A significantly larger portion of the population- $74 \%$ of the total population or 4.1 million people - are estimated to live within landscapes of perma-
Table 1 Most dominant land cover mosaics in the Lao PDR and their respective shares of the territory

\begin{tabular}{lcc}
\hline Composition of land cover mosaics & Share of land (\%) & Cumulative share of land (\%) \\
\hline Forest-open forest-shrub & 13.7 & 13.7 \\
Forest-open forest-shrub-swidden fields & 12.9 & 26.6 \\
Forest-shrub & 10.9 & 37.5 \\
Open forest-paddy & 4.2 & 41.7 \\
Forest-shrub-swidden fields & 4.0 & 45.6 \\
Forest-open forest-shrub-grassland & 3.9 & 49.6 \\
\hline
\end{tabular}




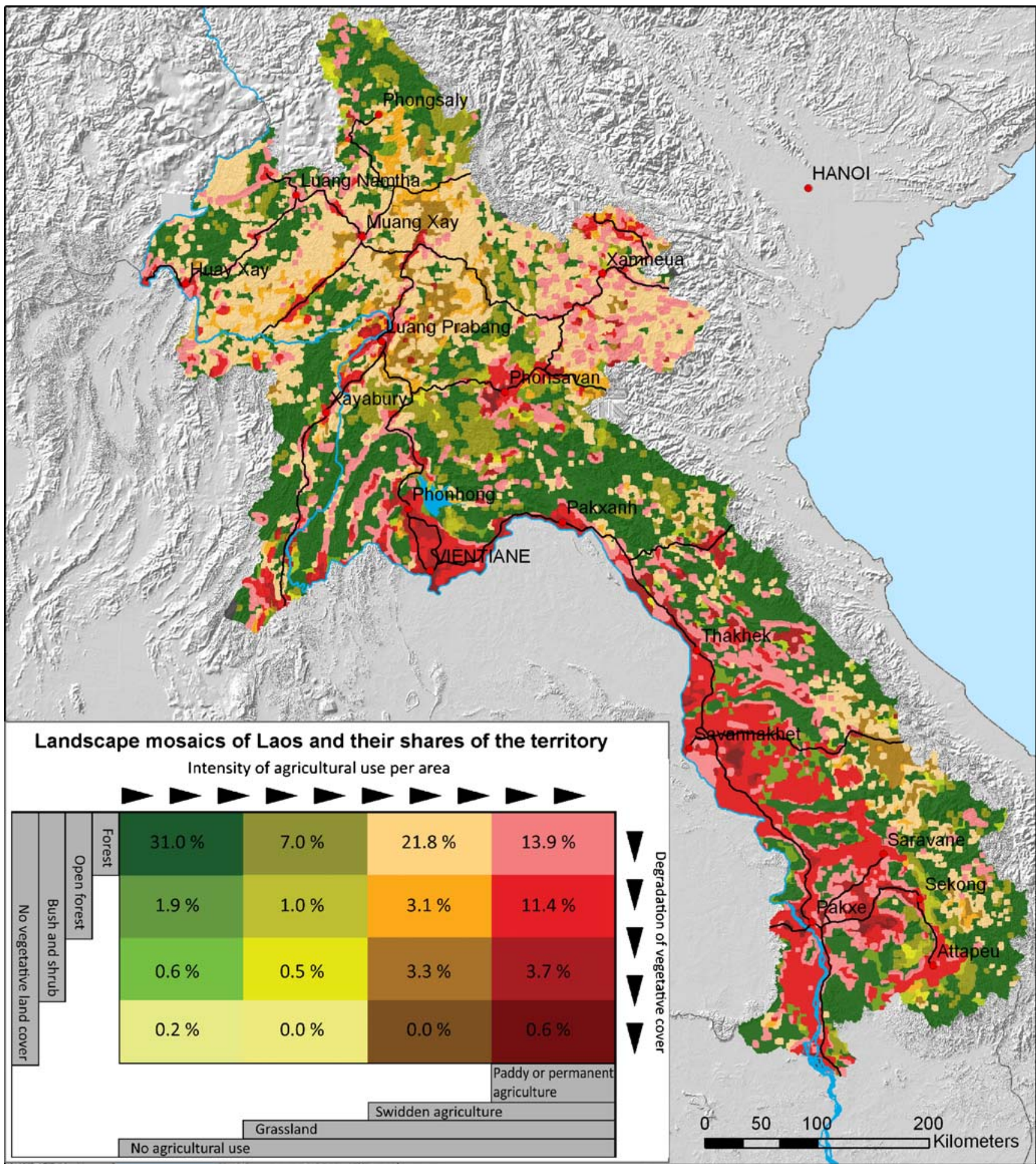

Fig. 7 Landscape mosaics of the Lao PDR and their respective share of the territory. Each mosaic represents a trade-off between the status of the vegetative cover on the one hand, and the agricultural intensification of land use on the other hand

nent agriculture. It is therefore not surprising that permanent agricultural landscapes have quite a high population density, amounting to 152 persons $/ \mathrm{km}^{2}$ on average, while swidden landscapes are less densely populated, with an average of 18.8 persons $/ \mathrm{km}^{2}$. It is noteworthy that these values are higher in swidden agriculture combined with open forest landscapes (24.2 persons $\left./ \mathrm{km}^{2}\right)$ and shrub (19.9 persons $/ \mathrm{km}^{2}$ ) but they are lower when swidden agriculture is practiced in dominantly forested landscapes (12.3 persons $/ \mathrm{km}^{2}$ ). 


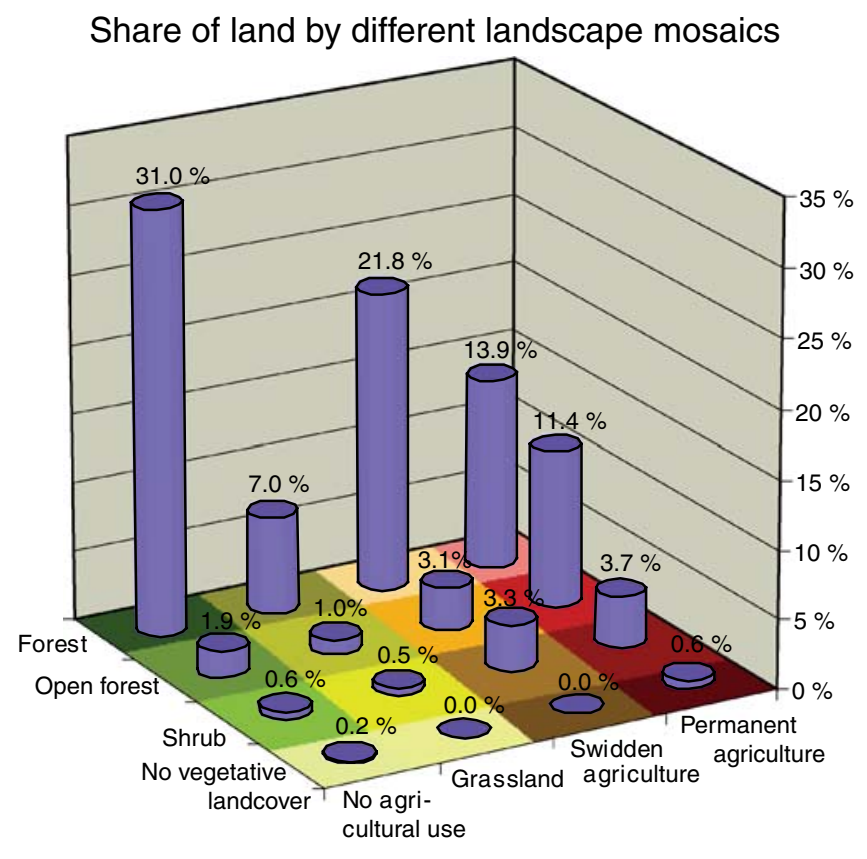

Share of total population within landscape mosaics

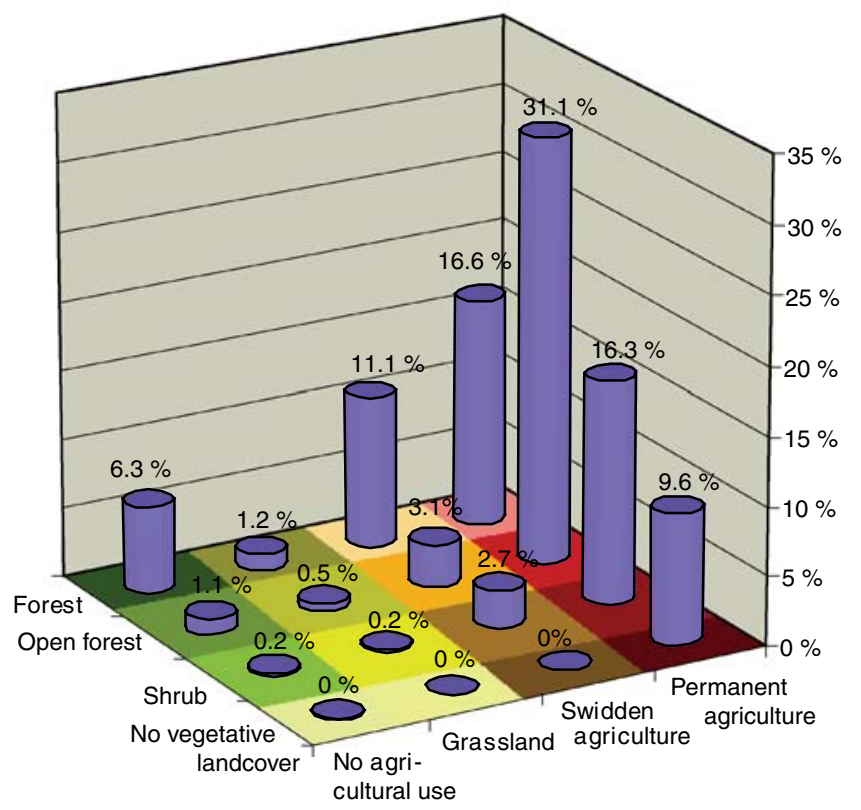

Fig. 8 Shares of total land and of total population within different types of landscape mosaics in the Lao PDR

\section{Discussion}

In this article we have presented an alternative way of describing landscape mosaics. Instead of approaching landscapes as 'land uses and their combinations in different patterns' (Tomich et al. 2004) we have asked in what spatial compositions land cover patches occur across the territory (i.e. land cover mosaics), and then interpreted these compositions in terms of human-environmental interactions. This approach and its results are discussed below.

One of the key characteristics of the approach consists of analyzing combinations and patterns of land cover patches before interpreting them in terms of their use. Thereby we try to point to a solution for the difficulty of extrapolating local contexts, to which interpretation is always bound. By delaying this interpretation and performing it at a higher level - in our case in the context of sub-national to national land use and development planning - we do, however, lose information at the local level-a level to which it is impossible to downscale our results in a meaningful way. In other words, having identified a landscape mosaic of swidden and shrub, we may accurately say that this region has lost its forest cover, and has not yet seen any transition to permanent agriculture. But we will not be able to define the precise use of the shrub in a certain place and time. Hence we have gained accuracy at the meso-level at the expense of accuracy at the micro-level. This insight underlines the importance of working with complementary approaches at different levels.
We believe that the proposed approach could be adapted to other situations in different regions. Yet, two important issues should still be considered. First, even if the analysis of land cover mosaics (step B1) using the moving window technique depends on neither a specific type of land cover data nor the human-environmental context of the study region, the ideal size of the window of analysis can not be derived empirically. It must be defined by the researchers. As mentioned earlier, the size of the window influences the composition and size of the resulting landscape mosaics. Therefore care must be taken in terms of the choice. We propose that the choice should be based on the expected spatial reach of the main actors inducing land cover change. Second, the contextual interpretation of land cover mosaics to define landscape mosaics (step B2) is again highly dependent on the research questions and on the development context of the study. Depending on the knowledge needs of such a context, the definition of the main features of the landscape mosaics could be adapted. We can imagine that agricultural intensification and deforestation could be replaced by other key issues of land change science such as urbanization, commercialization of land use, etc. (Turner et al. 2007) but also to support the analysis of ecosystem service provision and land functions (Verburg et al. 2009). Furthermore, it should also be possible to work with tripolar charts to define landscape mosaics (Riiters et al. 2009).

Finally we would like to stress the importance of the newly emerging geometries of the defined landscape mosaics. We believe that they are more accurate for the capture of complex spatial manifestations of the multi-dimensional land use 
strategies of rural households (Wiesmann et al. 2000) than are ordinary measures such as paddy land per community area or forests per watershed, etc. The persistent use of such spatial units for negotiation and planning of integrated development strategies reinforces the problem of the spatial mismatch between human and environmental systems, and eventually also between the problems and adequate solutions.

This study has intended to contribute to the filling-in of some of the current knowledge gaps of policy- and decision-making in the Lao PDR. The description of the landscape mosaics allows the making of reasoned estimations about the spatial share of different generalized land use types, the people living within these systems, and the trade-off in terms of loss of forest and vegetation cover. In the case of swidden agriculture, the combined information on the landscape mosaics and people proves particularly important. While reasonable and recent estimation of swidden landscapes where lacking in the past (SchmidtVogt et al. 2009), the assessment of people engaged in swidden cultivation is even more difficult (Mertz et al. 2009a). In the Lao PDR, our results will help to review and amend earlier estimations either focusing on the extent of swidden agriculture (Chazee 1994; Hansen 1997) or on people involved (Fujisaka 1991; GOL 2002). Furthermore, the new insights gained through this study will be particularly important in reflecting the mainstream of current development thinking, not only by governmental agencies, but also by international development partners. Among many such agencies, it is still widely believed that the most promising solution for lifting people out of rural poverty is through moving away from so-called environmentally destructive swidden agriculture to sedentary and permanent agriculture systems. Even if in the long term, this belief may be justifiable, it may cloud the view of the more immediate problems. The results show that swidden agriculture in 2002 was not only still being practiced in landscapes with relatively intact vegetative cover and considerably low population densities, but also that some landscapes of permanent agriculture were already manifesting high population densities. It seems, therefore, that public policies that artificially increase pressure on permanent agricultural land, e.g. through new land tenure policies, village relocation and/or merging programs, or the ceding of fallow land to investors for agricultural concessions (Chamberlain and Phomsombath 2002; Ducourtieux et al. 2005; Raintree 2003; Rigg 2005, 2006) should be carefully re-considered. Finally, we were also able to draw attention to the $7.5 \%$ of the population still living in mostly forested regions with no obvious agricultural use. These people and their livelihoods should not be ignored when making decisions and policies on environment and land development.
In summary, the depiction of landscape mosaics raises the issue of past and future pathways for land use in the Lao PDR. Spatial patterns suggest strongly that unpopulated and forested areas are transformed into swidden landscapes, which then gradually loose their vegetation cover. Depending on a series of agro-ecological, but also on socioeconomic factors, this is followed by a distinct rather than a gradual transformation into permanent systems. Against this backdrop, current interventions by multiple development stakeholders, which often pursue the goals of food security, poverty alleviation, and sustainable natural resource management, could be reviewed. Despite the preference for simple solutions to complex problems, different strategies for different types of landscape mosaics should be developed for the pursuit of those goals. As landscape mosaics vary across the territory, spatially differentiated strategies must be applied across the country. In other words, there can be no universal solutions or panaceas for sustainable transitions of human-environmental systems (Ostrom 2007). Conversely, the map of landscape mosaics could serve as a tool in assisting development partners in targeting intervention sites and supporting the out-scaling of innovative solutions from one context to another. We can imagine that for example the successful establishment of a livestock breeding and marketing programme in a degraded swidden cultivation landscape could be difficult to transfer to a nearby village where permanent cash-cropping represents the main focus of revenues. Using the landscape mosaics data, other even distant regions could be identified, where similar limitations in terms of population density and scarce land resources indicate a more promising context for out-scaling.

\section{Conclusions and Outlook}

In this article we have presented an alternative approach for relating land cover information to human-environmental interactions over large areas - an issue which remains a key challenge of land change science in general and to research on swidden agriculture in particular. We propose the transfer of the interpretation of land cover in terms of its use from the local to a meso-level of spatial scale in order to avoid the often impossible extrapolation of the specificities of local contexts. Based on an initial dialogue with development partners we believe that this information helps to fill-in the growing gap between the scarce, but urgently needed, knowledge for informed decision-making at this level. As development in the Lao PDR follows an ever accelerating economic pace, and as the number of interventions impacting on the use of land grows rapidly, spatial patterns become more complex, and no one district or village seems to be comparable to another. The description 
of landscape mosaics thereby helps to balance the requirement for a highly contextual perspective with the need for generalization at higher levels. We think that such a balanced picture is particularly necessary to design policies and inform decisions in the field of swidden systems, where spatial and thematic differentiation is a precondition to avoid the trap of ideological, political, or technical bias and over-simplification.

We do not think of this knowledge at meso-level as an alternative to micro- or macro-level studies, but rather, as a necessary complement to bridge and initiate a dialogue across different scales. Accordingly, a threefold need for future research can be identified. First, the sixteen landscape mosaics should be related to local case studies for a better understanding of the underlying land change processes and enhancing our knowledge about related trajectories of land use. The transitions between swidden and permanent agriculture thereby seem to be of particular importance. Second, research at the meso-level also should be continued. Landscape mosaics can be related to other available socio-economic data layers such as poverty and ethnicity. A more realistic picture of the poverty situation in different swidden landscape mosaics is expected to be particularly revealing. Finally, a spatially explicit analysis of the actors influencing and governing different landscape mosaics will be crucial for further policy- and decisionmaking support.

Acknowledgments The authors acknowledge support from the Swiss National Centre of Competence in Research (NCCR) NorthSouth: Research Partnerships for Mitigating Syndromes of Global Change, co-funded by the Swiss National Science Foundation (SNF) and the Swiss Agency for Development and Cooperation (SDC). Furthermore, this research also contributes to the Global Land Project (GLP) and has benefited from the collaboration within this network.

Open Access This article is distributed under the terms of the Creative Commons Attribution Noncommercial License which permits any noncommercial use, distribution, and reproduction in any medium, provided the original author(s) and source are credited.

\section{References}

Achard, F., Eva, H., Stibig, H. J., Mayaux, P., Gallego, J., Richards, T., and Malingreau, J. P. (2002). Determination of Deforestation Rates of the World's Humid Tropical Forests. Science 297: 999-1002. doi: $10.1126 /$ science. 1070656.

ADB. (2001). Participatory Poverty Assessment: Lao People's Democratic Republic. Asian Development Bank, Vientiane, Lao PDR.

Badenoch, N. (1999). Watershed Management and Upland Development in Lao PDR: A Synthesis of Policy Issues. World Resource Institute, Washington.

Cash, D. W., Clark, W. C., Alcock, F., Dickson, N. M., Eckley, N., Guston, D. H., Jager, J., and Mitchell, R. B. (2003). Knowledge Systems for Sustainable Development. Proceedings of the
National Academy of Sciences of the United States of America 100: 8086-8091. doi:10.1073/pnas.1231332100.

Chamberlain, J. R., and Phomsombath, P. (2002). Poverty Alleviation for All: Potentials and Options for Peoples in the Uplands. SIDA, Vientiane, Lao PDR.

Chazee, L. (1994). Shifting Cultivation Practices in Laos: Present Systems and their Future. UNDP/Ministry of Agriculture and Forestry, Vientiane, Lao PDR.

Ducourtieux, O., Laffort, J. R., and Sacklokham, S. (2005). Land Policy and Farming Practices in Laos. Development and Change 36: 499-526.

Epprecht, M., Minot, N., Dewina, R., Messerli, P., and Heinimann, A. (2008). The Geography of Poverty and Inequality in the Lao PDR. Geographica Bernensia, Bern.

Foley, J. A., DeFries, R., Asner, G. P., Barford, C., Bonan, G., Carpenter, S. R., Chapin, F. S., Coe, M. T., Daily, G. C., Gibbs, H. K., Helkowski, J. H., Holloway, T., Howard, E. A., Kucharik, C. J., Monfreda, C., Patz, J. A., Prentice, I. C., Ramankutty, N., and Snyder, P. K. (2005). Global Consequences of Land Use. Science 409: 570-573. doi:10.1126/science.1111772.

Fox, J. (2000). How Blaming 'Slash and Burn' Farmers is Deforesting Mainland Southeast Asia. East-West Center, Honolulu.

Fujisaka, S. (1991). A Diagnostic Survey of Shifting Cultivation in Northern Laos: Targeting Research to Improve Sustainability and Productivity. Agroforestry Systems 13: 95-109. doi:10.1007/ BF00140235.

Fullbrook, D. (2006). Beijing pulls Laos into its orbit. Asia Times Online.

Geist, H., and Lambin, E. (2001). What Drives Tropical Deforestation? A Meta-analysis of Proximate and Underlying Causes of Deforestation Based on Subnational Case Study Evidence. Leuven, Belgium.

Geist, H. J., and Lambin, E. F. (2004). Dynamic Causal Patterns of Desertification. Bioscience 54: 817.

Giddens, A. (1991). Modernity and Self-Identity. Self and Society in the Late Modern Age. Polity, Cambridge.

GLP (2005). Science Plan and Implementation Strategy. IGBP Secretariat, Stockholm.

GOL (1999). The Government's Strategic Vision for the Agricultural Sector. Ministry of Agriculture and Forestry, Vientiane, Lao PDR.

GOL (2002). Agricultural Statistics: Yearbook 2001. Ministry of Agriculture and Forestry, Vientiane, Lao PDR.

GOL. (2005). Government of Lao PDR: Report on the Assessment of Forest Cover and Land Use Between 1992 and 2002. Ministry of Agriculture and Forestry, Department of Forestry, Vientiane, Lao PDR.

GOL. (2006a). Government of Lao, PDR: National Agrobiodiversity Strategy, Vientiane, Laos.

GOL (2006b). Results from the Population and Housing Census of 2005. Steering Committee for the Census of the Population and Housing, Vientiane Capital, Lao PDR.

Government of Lao, P.D.R. (2000). Poverty in the Lao PDR. Participatory Poverty Assessment (PPA), Vientiane, Lao PDR.

Hansen, P. K. (1997). Shifting cultivation development in Northern Laos Upland Farming System in the Laos PDR: Problems and Opportunities for Livestock, Vientiane, Lao PDR.

Heinimann, A. (2006). Patterns of Land Cover Change in the Lower Mekong Basin. The Relevance of Mesoscale Approaches. University of Bern, Switzerland.

Hirsch, P. (2000). Underlying Causes of Deforestation in the Mekong Region. Australian Mekong Resource Centre, Sydney.

Hirsch, P. (2001). Globalisation, Regionalisation and Local Voices: The Asian Development Bank and Rescaled Politics of Environment in the Mekong Region. Singapore Journal of Tropical Geography 22: 237-251. doi:10.1111/1467-9493.00108.

Hurni, H. (1996). Precious Earth: From Soil and Water Conservation to Sustainable Land Management. International Soil Conservation 
Organisation (ICSO) and Centre for Development and Environment (CDE), Geographica Bernensia, Bern.

International Monetary Fund (IMF) (2008). World Economic Outlook Database 2008 [Online]. www.imf.org (verified 6.12.2008).

IUCN (2006). Strategic Framework 2007-2011. Conservation for Sustainable Livelihoods in Lao PDR-Refreshed thinking. The World Conservation Union (IUCN), Lao PDR Country Office, Vientiane, Lao PDR.

Kates, R. W., Clark, W. C., Corell, R., Hall, J. M., Jaeger, C. C., Lowe, I., McCarthy, J. J., Schellnhuber, H. J., Bolin, B., Dickson, N. M., Faucheux, S., Gallopin, G. C., Grübler, A., Huntley, B., Jäger, J., Jodha, N. S., Kasperson, R. E., Mabogunje, A., Matson, P., Mooney, H., Moore, B. III, O'Riordan, T., and Svedin, U. (2001). Environment and Development: Sustainability Science. Science 292: 641-642. doi:10.1126/science.1059386.

Lambin, E. F., and Geist, H. J. (2004). Global Land Use Land Cover: What Have We Learned so Far? LUCC Newsletter.

Lambin, E. F., Geist, H. J., and Lepers, E. (2003). Dynamics of Land Use and Land Cover Change in Tropical Regions. Annual Review of Environmental Resources 28: 205-241. doi:10.1146/ annurev.energy.28.050302.105459.

Lepers, E., Lambin, E. F., Janetos, A. C., deFries, R., Achard, F., Ramankutty, N., and Scholes, R. J. (2005). A Synthesis of Information on Rapid Land-Cover Change for the Period 19812000. Bioscience 55: 115-124. doi:10.1641/0006-3568(2005) 055[0115:ASOIOR]2.0.CO;2.

Levin, S. A. (1997). Management and the Problem of Scale. Ecology and Society 1: 113

Long, N. (2001). Development Sociology. Actor Perspectives. Routledge, London, UK.

McMichael, A. J., Butler, C. D., and Folke, C. (2003). New Visions for Addressing Sustainability. Science 302: 1919-1920.

Mertz, O., Padoch, C., Fox, J., Cramb, R. A., Leisz, S. J., Nguyen, T. L., and Vien, T. D. (2009a). Swidden Change in Southeast Asia: Understanding Causes and Consequences. Human Ecology, this issue

Mertz, O., Leisz, S., Heinimann, A., Rerkasem, K., Thiha, Dressler, W., Cu, P. V., Vu, K. C., Schmidt-Vogt, D., Colfer, C. J. P., Epprecht, M., Padoch, C., and Potter, L. (2009b). Who Counts? The Demography of Swidden Cultivators. Human Ecology, this issue

Messerli, P. (2004). Alternatives à la culture sur brûlis sur la Falaise Est de Madagascar: Stratégies en vue d'une gestion plus durable des terres. Geographica Bernensia, Bern.

Messerli, P., and Heinimann, A. (2007). Development intervention disparities and the poverty-environment nexus in the Lower Mekong Basin: understanding environmental services in a mesoscale perspective. In Gebbie, L. et al. (ed.), Proceedings of the International Conference on Sustainable Sloping Lands and Watershed Management: linking research to strengthen upland policies and practices. National Agriculture and Forestry Research Institute, Vientiane, Lao PDR, p. 563.

Messerli, P., Heinimann, A., Epprecht, M., Phonesaly, S., Thiraka, C., and Minot, N. (eds.) (2008). Socio-Economic Atlas of the Lao PDR-An Analysis Based on the 2005 Population and Housing Census. Geographica Bernensis, Bern and Vientiane.

Mittermeier, R. A., Gil, P., Hoffmann, M., Pilgrim, J., Brooks, T., Mittermeier, C. G., Lamoreux, J., and Fonseca, A. B. (2005). Hotspot Revisited: Earth's Biologically Richest and Most Endangered Terrestrial Ecoregions. Conservation International, Washington.

Myers, N., Mittermeier, R. A., Mittermeier, C. G., da Fonseca, G. A. B., and Kent, J. (2000). Biodiversity hotspots for conservation priorities. Nature 403: 853-858. doi:10.1038/35002501.

Ostrom, E. (2007). A diagnostic approach for going beyond panaceas. PNAS 104: 15181-15187. doi:10.1073/pnas.0702288104.

Padoch, C., Coffey, K., Mertz, O., Leisz, S., Fox, J., and Wadley, R. L. (2007). The Demise of Swidden in Southeast Asia? Local Realities and Regional Ambiguities. Geografisk Tidsskrift-Danish Journal of Geography 107: 29-41.

Parnwell, M. J. G., Bryant, R. L. (eds.) (1996). Environmental Change in South-east Asia: People, Politics and Sustainable Development. Review Routledge, London.

Qiang, M., and Broadhead, S. (eds.) (2002). An Overview of the Forest Production Statistics in South and Southeast Asia. Food and Agricultural Organisation of the United Nations (FAO), Rome.

Raintree, J. B. (2003). Social perspectives on food security in the uplands of Northern Laos. Socio-economic Unit, National Agriculture and Forestry Research Institute (NAFRI). [Online].

Rigg, J. D. (2005). Living in Transition in Laos: Market Integration in Southeast Asia. Routledge, London.

Rigg, J. D. (2006). Forests, Marketization, Livelihoods and the Poor in the Lao PDR. Land Degradation and Development 17: 123 133. doi: $10.1002 / \mathrm{ldr} .719$.

Riiters, K. H., Wickham, J. D., and Wade, T. G. (2009). An Indicator of Forest Dynamics Using a Shifting Landscape Mosaic. Ecological Indicators 9: 107-117. doi:10.1016/j.ecolind.2008.02.003.

Rudel, T. K., Flescher, K., Bates, D., Baptista, S., and Holmgren, P. (2000). Tropical Deforestation Literature: Geographical and Historical Patterns. Unasylva 51: 11-18.

Schmidt-Vogt, D., Leisz, S., Mertz, O., Heinimann, A., Thiha, Messerli, P., Epprecht, M., Cu, P. V., Vu, K. C., Hardiono, M., and Truong, D. M. (2009). An Assessment of Trends in the Extent of Swidden in Southeast Asia. Human Ecology, this issue

Tomich, T. P., Chomitz, K., Francisco, H., Izac, A. -M. N., Murdiyarso, D., Ratner, B. D., Thomas, D. E., and van Noordwijk, M. (2004). Policy Analysis and Environmental Problems at Diffferent Scales: Asking the Right Questions. Agriculture, Ecosystems and Environment 104: 5-18. doi:10.1016/j.agee.2004.01.003.

Turner, B. L., Lambin, E. F., and Reenberg, A. (2007). The Emergence of Land Change Science for Global Environmental Change and Sustainability. PNAS 104: 20666-20671. doi:10.1073/pnas. 0704119104

UNDP (2007). Human Development Report. United Nations Development Report 2008, New York.

Verburg, P. H., Van de Steeg, J., Veldkamp, A., and Willemen, L. (2009). From Land Cover Change to Land Function Dymnamics: A Major Challenge to Improve Characterization. Journal of Environmental Management 90: 31327-1335.

WFP (2007). Lao PDR: Comprehensive Food Security and Vulnerability Analysis. World Food Programme, Vientiane, Lao PDR.

Wiesmann, U. (1998). Sustainable Regional Development in Rural Africa: Conceptual Framework and Case Studies from Kenya. University of Berne Switzerland, Institute of Geography, Berne, Switzerland

Wiesmann, U., Gichuki, F., Kiteme, B. P., and Liniger, H. P. (2000). Mitigating Conflicts over Scarce Water Resources in the Highland-Lowland System of Mount Kenya. Mountain Research and Development 20: 10-15. doi:10.1659/0276-4741(2000)020 [0010:MCOSWR]2.0.CO;2.

Woodcock, C. E., and Ozdogan, M. (2004). Trends in Land Cover Mapping and Monitoring. Springer, Berlin.

Woods, K. (2003). Transboundary Environmental Governance in the Mekong River Basin: Civil Society Spaces for Transboundary Participation. Presented at "Politics of the Commons: Articulating Development and Strengthening Local Practices", Chiang Mai, Thailand, July 11-14, 2003.

World Bank (2008a). Lao PDR Environment Monitor. The World Bank, Vientiane, Lao PDR.

World Bank (2008b). Lao PDR Economic Monitor. The World Bank Office, Vientiane.

Wu, J., and Hobbs, R. (2007). Key Topics in Landscape Ecology. Cambridge University Press, Cambridge. 